\title{
Associations Among Serum Lipoprotein(a) Levels, Apolipoprotein(a) Phenotypes, and Myocardial Infarction in Patients With Extremely Low and High Levels of Serum Lipoprotein(a)
}

\author{
Keijiro Saku, MD; Bo Zhang, PhD; Rui Liu, PhD; \\ Kazuyuki Shirai, MD; Kikuo Arakawa, MD
}

\begin{abstract}
A high serum lipoprotein(a) [Lp(a)] level, which is genetically determined by apolipoprotein(a) [apo(a)] size polymorphism, is an independent risk factor for coronary atherosclerosis. However, the associations among Lp(a) levels, apo(a) phenotypes, and myocardial infarction (MI) have not been studied. Patients with MI (cases, $\mathrm{n}=101, \mathrm{M} / \mathrm{F}: 86 / 15$, age: $62 \pm 10 \mathrm{y})$ and control subjects (n=92, M/F: $53 / 39$, age: $58 \pm 14 \mathrm{y}$ ) were classified into quintile groups (Groups I to V) according to $\mathrm{Lp}(\mathrm{a})$ levels. Apo(a) isoform phenotyping was performed by a sensitive, high-resolution technique using sodium dodecyl sulfate-agarose/gradient polyacrylamide gel electrophoresis (3-6\%), which identified 26 different apo(a) phenotypes, including a null type. Groups with higher Lp(a) levels (Groups II, III, and V) had higher percentages of MI patients than that with the lowest Lp(a) levels (Group I) $(54 \%, 56 \%$, or $75 \%$ vs. $32 \%, \mathrm{p}<0.05)$. Groups with different $\mathrm{Lp}(\mathrm{a})$ levels had different frequency distributions of apo(a) isoprotein phenotypes: Groups II, III, IV, and V, which had increasing Lp(a) levels, had increasingly higher percentages of smaller isoforms (A1-A4, A5-A9) and decreasingly lower percentages of large isoforms (A10-A20, A21-A25) compared to Group I. An apparent inverse relationship existed between $\mathrm{Lp}(\mathrm{a})$ and the apo(a) phenotype. Subjects with the highest $\mathrm{Lp}(\mathrm{a})$ levels (Group V) had significantly $(\mathrm{p}<0.05)$ higher serum levels of total cholesterol, apo B, and Lp(a). Patients with MI and the controls had different distributions of apo(a) phenotypes: ie, more small isoforms and more large size isoforms, respectively (A1-A4/A5-A9/A10-A20/A21-A25: 35.7\%/27.7\%/20.8\%/15.8\% and 22.8\%/23.9\%/29.4\%/23.9\%, respectively). $\mathrm{Lp}$ (a) (parameter estimate \pm standard error: $0.70 \pm 0.20$, WaldX ${ }^{2}=12.4, \mathrm{p}=0.0004$ ), apo(a) phenotype $\left(-0.43 \pm 0.15\right.$, WaldX $\left.{ }^{2}=8.17, p=0.004\right)$, High-density lipoprotein-cholesterol, apo A-I, and apo B were significantly associated with MI after adjusting for age, gender, and conventional risk factors, as assessed by a univariate logistic regression analysis. The association between Lp(a) and MI was independent of the apo(a) phenotype, but the association between the apo(a) phenotype and MI was not independent of $\mathrm{Lp}(\mathrm{a})$, as assessed by a multivariate logistic regression analysis. This association was not influenced by other MI- or Lp(a)-related lipid variables. These results suggest that apo(a) phenotype contributes to, but does not completely explain, the increased $\mathrm{Lp}(\mathrm{a})$ levels in MI. A stepwise logistic regression analysis with and without $\mathrm{Lp}(\mathrm{a})$ in the model identified $\mathrm{Lp}(\mathrm{a})$ and the apo(a) phenotype as significant predictors for MI, respectively. (Jpn Circ J 1999; 63: 659-665)
\end{abstract}

Key Words: Apolipoprotein(a); Lipoprotein(a); Myocardial infarction; Phenotypes

$\mathbf{L}$ ipoprotein(a) $[\mathrm{Lp}(\mathrm{a})]$ is a heterogeneous lipoprotein ${ }^{1}$ that incorporates a low-density lipoprotein (LDL) particle and highly polymorphic apolipoprotein(a) [apo(a)], which is covalently linked to the apolipoprotein B moiety of the LDL by a single disulfide bridge?,3 Apo(a) is highly homologous to plasminogen and affects the human coagulation system.,5 The apo(a) gene locus is the major gene that controls plasma $\mathrm{Lp}$ (a) concentrations, 6,7 The alleles at this locus determine the size polymorphism of apo(a), which is the result of a variable number of expressed

(Received April 2, 1999; revised manuscript received May 24, 1999; accepted May 27, 1999)

Department of Internal Medicine, Fukuoka University School of Medicine, Fukuoka, Japan

Part of this work was presented at the 70th EAS (European Atherosclerosis Society) Congress, Geneva, Switzerland, 7 September 1998. Mailing address: Keijiro Saku, MD, Department of Internal Medicine, Fukuoka University School of Medicine, 7-45-1 Nanakuma Jonan-ku, Fukuoka 814-0180, Japan. E-mail: hh035399@msat.fukuoka-u.ac.jp kringle IV repeats, ${ }^{6-8}$ and is assessed by apo(a) genotyping? Utermann et al first reported a size polymorphism of 6 apo(a) isoforms with different molecular weights, and other researchers have detected additional apo(a) isoforms using different detection methods 9,10 We recently detected 26 different apo(a) alleles, including a null allele, at the apo(a) locus by a sensitive high-resolution technique using sodium dodecyl sulfate (SDS)-agrose/gradient polyacrylamide gel electrophoresis (PAGE)!1 Approximately $75 \%$ of the subjects had a double band of apo(a), and the remaining subjects had a single band. An inverse relationship has been demonstrated between plasma $\mathrm{Lp}(\mathrm{a})$ concentrations and the size of apo(a), ${ }^{8,11}$ and a smaller Lp(a) band was well correlated with $L p(a)$ levels in double-banded phenotypes!1-13

High plasma levels of $\mathrm{Lp}(\mathrm{a})$ have been shown to be associated with myocardial infarction (MI) ${ }^{14-17}$ although this association was not confirmed by 2 prospective studies! 18,19 Apo(a) size polymorphism has been shown to be inversely associated with the risk of coronary heart disease (CHD) in 
patients with end-stage renal disease ${ }^{20}$ hypertension $(\mathrm{HT})^{21}$ or diabetes mellitus (DM) $)^{12}$ those undergoing coronary bypass surgery 22 and hemodialysis patients with or without DM $!^{3}$ However, the relation between apo(a) isoform size polymorphism and MI has rarely been studied ${ }^{23}$ and it would be interesting to determine whether, and how much, apo(a) isoform size polymorphism contributes to the increased serum $\mathrm{Lp}(\mathrm{a})$ levels in MI, because an inverse relation does exist between plasma $\mathrm{Lp}(\mathrm{a})$ levels and apo(a) size.,11

In the present study, we studied the associations among serum Lp(a) levels, apo(a) phenotyps, and MI. Because large differences in $\mathrm{Lp}(\mathrm{a})$ levels can be used to predict important associations, we initially targeted patients with MI as well as normal controls, and then selected the subjects with extremely low or high serum Lp(a) levels from among these.

\section{Methods}

\section{Study Patients}

The subjects, consisting of 101 patients with MI and 92 normal controls at Fukuoka University Hospital, were classified into 5 groups according to quintile values of serum Lp(a) levels: Group I, $n=41, L p(a) \leq 10 \mathrm{mg} / \mathrm{dl}$; Group II, $\mathrm{n}=39,10 \mathrm{mg} / \mathrm{dl}<\mathrm{Lp}(\mathrm{a}) \leq 20 \mathrm{mg} / \mathrm{dl}$; Group III, $\mathrm{n}=36,20$ $\mathrm{mg} / \mathrm{dl}<\mathrm{Lp}(\mathrm{a}) \leq 29 \mathrm{mg} / \mathrm{dl}$; Group IV, $\mathrm{n}=37,29 \mathrm{mg} / \mathrm{dl}<\mathrm{Lp}(\mathrm{a})$ $<48 \mathrm{mg} / \mathrm{dl}$; and Group V, n=40, Lp(a) $\geq 48 \mathrm{mg} / \mathrm{dl}$. Cases were defined as patients with old MI; the diagnosis of MI was made from symptoms, electrocardiogram (ECG) and serum creatine kinase isoenzyme (CK-MB) of more than twice the upper level of normal. Cardiac catheterization analysis, including coronary angiography (CAG) and left ventriculography, were performed in the acute phase, and the definitive diagnosis of MI was made. Controls were defined as those who had normal coronary arteries $(<25 \%$ stenosis) as proven by CAG and who had no clinical evidence of CHD on history and exercise ECG. Patients with acute MI (within 3 weeks of the onset), heart failure (Killip Class $\geq 2$ after MI), vascular disease (aortitis treated by prednisolone), hepatic dysfunction (viral and non-viral, transaminases more than 3 times the normal value), or uncontrollable DM were excluded from the study. Patients with systolic or diastolic blood pressure greater than 160 $\mathrm{mmHg}$ or $95 \mathrm{mmHg}$, respectively, or who were under antihypertensive treatment were considered to have HT. Patients under treatment for DM and/or with symptoms of $\mathrm{DM}$ and a fasting glucose concentration $\geq 126 \mathrm{mg} / \mathrm{dl}$ were considered to have DM. Otherwise, the results of a 75-g glucose tolerance test were used to diagnose DM. All of the women were in menopause, but none were receiving hormone replacement therapy. This study was approved by the ethics committee of Fukuoka University Hospital and informed consent was obtained from each patient.

\section{Coronary Angiography}

Coronary arteries were cannulated by the Judkins technique $^{24}$ with $5 \mathrm{~F}$ catheters, and recorded on Kodak $35-\mathrm{mm}$ cinefilm at a rate of 25 frames/s. Coronary arteries were divided into 15 segments, according to the classification of the American Heart Association Grading Committee. The presence of stenosis was determined using a computerassisted CAG analysis system (Mipron 1; Kontron Co) after the direct intracoronary injection of isosorbide dinitrate (ISDN) (2.5 mg/5-ml solution). One minute after the injection of ISDN through the Judkins catheter, which took $20 \mathrm{~s}, \mathrm{CAG}$ was performed from several projections during 7 min, as described previously 25,26

Determination of Serum Lipids, Lipoproteins, Apolipoproteins, and Apo(a) Isoform Phenotype

A blood sample was drawn in the morning after an overnight fast. Serum total cholesterol (TC) and triglyceride (TG) concentrations were determined enzymatically. High-density lipoprotein-cholesterol (HDL-C) was determined by the heparin $\mathrm{Ca}^{2+}$ precipitation method. HDL subfractions (HDL2 and HDL3) were separated by standard sequential preparative ultracentrifugation techniques. Apolipoprotein (apo) A-I, apo A-II, apo B, apo C-II, apo CIII, and apo $\mathrm{E}$ were determined by the turbidity immunoassay method ${ }^{27}$ Serum Lp(a) was determined by enzymelinleed immunosorbent assay (ELISA) using a Tint Eliza Lp(a) kit (Biopool, Sweden) ${ }^{28}$ For all measurements in our laboratory, the interassay and intra-assay coefficients of variation were less than $7 \%$ and $5 \%$, respectively, and blinded quality-control specimens were included in each assay.

Apo(a) phenotyping was performed by the method of Kikuchi et al ${ }^{11}$ as we described previously!12,13

\section{Statistical Analysis}

Statistical analysis was performed using the SAS Software Package (Version 6.12, Statistical Analysis System, SAS Institute Inc, Cary, NC, USA). Categorical variables (such as gender) and frequency distribution patterns of the apo(a) phenotype between groups were compared by a chi-square analysis. The distribution of continuous variables was examined by the Shapiro-Wilk test ${ }^{29}$ Quintile values of $\mathrm{Lp}$ (a) (20th percentile: $10 \mathrm{mg} / \mathrm{dl}$; 40th percentile: $20 \mathrm{mg} / \mathrm{dl}$; 60 th percentile: $29 \mathrm{mg} / \mathrm{dl}$; 80 th percentile: $48 \mathrm{mg} / \mathrm{dl}$ ) were used to classify subjects into 5 groups with increasing $\mathrm{Lp}(\mathrm{a})$ levels from Group I to Group $\mathrm{V}$. Differences of continuous variables between groups were examined by an analysis of variance (ANOVA), and age and gender were adjusted for by an analysis of covariance 30 The associations among serum $\mathrm{Lp}(\mathrm{a})$ levels, apo(a) phenotype, and MI after controlling for age, gender, and potentially confounding variables were evaluated by a multiple logistic function analysis ${ }^{3}{ }^{1}$ For logistic parameter estimates, we showed the standard error. Independent associations of variables with MI were also examined by a stepwise logistic regression analysis $3{ }^{31}$ All $\mathrm{p}$ values are 2 -tailed. The significance level was considered to be $5 \%$ unless otherwise indicated.

\section{Results}

Table 1 shows the clinical characteristics of the 5 groups of subjects classified according to the quintile values of serum Lp(a) levels, and the frequency distribution of apo(a) isoform phenotypes. Age, gender, body mass index (BMI), and prevalence of HT, DM, and smokers were not significantly different among the 5 groups. However, there were significantly $(\mathrm{p}<0.05)$ more MI patients in each of Groups II, III, and/or V (with extremely high $\mathrm{Lp}$ (a) levels) than in Group I (with extremely low Lp(a) levels), and the linear trend of the prevalence of MI across these quintile groups of Lp(a) was significant as assessed by the Mantel-Haenszel chi-square test. The frequency distributions of the apo(a) phenotypes in Groups II, III, IV, and/or V were different 
Table 1 Clinical Characteristics of Subjects Grouped According to Quintile Values of Serum Levels of Lipoprotein (a) [Lp(a)], and the Frequency Distribution of the Apolipoprotein(a) [Apo(a)] Isoform Phenotype

\begin{tabular}{lccccc}
\hline \hline & $\begin{array}{c}\text { Group I } \\
(n=41)\end{array}$ & $\begin{array}{c}\text { Group II } \\
(n=39)\end{array}$ & $\begin{array}{c}\text { Group III } \\
(n=36)\end{array}$ & $\begin{array}{c}\text { Group IV } \\
(n=37)\end{array}$ & $\begin{array}{c}\text { Group V } \\
(n=40)\end{array}$ \\
\hline Age (years) & $59 \pm 13$ & $59 \pm 15$ & $60 \pm 11$ & $63 \pm 13$ & $60 \pm 11$ \\
Gender (male/female) & $29 / 12$ & $31 / 8$ & $28 / 8$ & $23 / 14$ & $28 / 12$ \\
Body mass index $\left(\mathrm{kg} / \mathrm{m}^{2}\right)$ & $22.4 \pm 2.8$ & $23.5 \pm 3.2$ & $23.0 \pm 2.6$ & $23.4 \pm 2.7$ & $23.6 \pm 3.8$ \\
Hypertension $(\%)$ & 34 & 33 & 53 & 46 & 25 \\
Diabetes mellitus $(\%)$ & 20 & 38 & 25 & 27 & 18 \\
Smokers (\%) & 46 & 51 & 58 & 35 & 60 \\
Myocardial infarction $(\%)$ & 32 & $54 *$ & $56 *$ & 46 & $75^{* \dagger}$ \\
Apo(a) isoform phenotype & & $5 *$ & $6 *$ & $12 *$ & $34^{* \dagger}$ \\
I (Al-A4) & 0 & 12 & 8 & 21 & 3 \\
II (A5-A9) & 6 & 17 & 17 & 3 & 3 \\
III (A10-A20) & 8 & 5 & 5 & 1 & 0 \\
IV (A21-A25) & 27 & & & &
\end{tabular}

Group I, subjects with Lp(a) levels $\leq 10 \mathrm{mg} / \mathrm{dl}$ (20th percentile); Group II, subjects with Lp(a) levels $>10 \mathrm{mg} / \mathrm{dl}$ and $\leq 20 \mathrm{mg} / \mathrm{dl}$ (40th percentile); Group III, subjects with Lp(a) levels $>20 \mathrm{mg} / \mathrm{dl}$ and $\leq 29 \mathrm{mg} / \mathrm{dl}$ (60th percentile); Group IV, subjects with Lp(a) levels $>29 \mathrm{mg} / \mathrm{dl}$ and $<48 \mathrm{mg} / \mathrm{dl}$ (80th percentile); Group V, subjects with Lp(a) levels $\leq 48 \mathrm{mg} / \mathrm{dl}$.

${ }^{*} p<0.05$ vs Group I, by chi-square analysis. ${ }^{\dagger} p<0.05$, linear trend as assessed by the Mantel-Haenszel chi-square test.

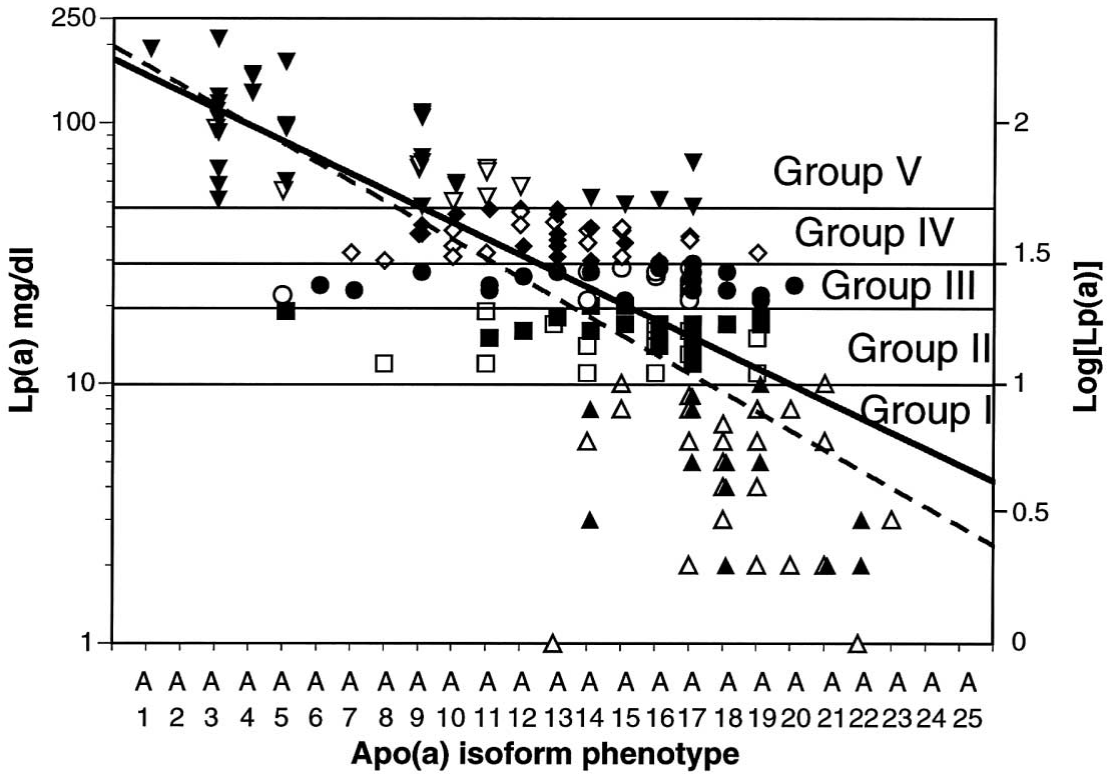

Fig 1. Plot of serum lipoprotein(a) [Lp(a)] levels versus the apolipoprotein(a) [apo(a)] isoform phenotype in subjects grouped according to quintile values of $\mathrm{Lp}(\mathrm{a})$ [Group I (quintile I), $\Delta$ (patients with MI) and $\triangle$ (controls); Group II (quintile II), $\mathbf{a}$ (patients with MI) and $\square$ (controls); Group III (quintile III), - (patients with MI) and $\bigcirc$ (controls); Group IV (quintile IV), (patients with MI) and $\diamond$ (controls); Group V (quintile V), $\mathbf{v}$ (patients with MI) and $\nabla$ (controls)]. $(\mathrm{p}<0.05)$ from those in Group I; Groups II, III, IV and V had more small isoforms (low molecular weight, A1-A4 and A5-A9) and fewer large isoforms (high molecular weight, A10-A20 and A21-A25) compared with Group I.

Fig 1 shows a plot of serum $\operatorname{Lp}(\mathrm{a})$ levels vs the apo(a) isoform phenotype in all of the subjects. An inverse relationship between serum Lp(a) levels and apo(a) size polymorphism was apparent: Group I subjects, who had the lowest Lp(a) levels, were associated with high molecular weight apo(a) phenotypes (Fig 1, left); Group V subjects, who had the highest $\mathrm{Lp}(\mathrm{a})$ levels, were associated with low molecular weight apo(a) phenotypes (Fig 1, right). Lp(a) levels were strongly and inversely related to apo(a) isoform phenotypes in all of the subjects combined $(\mathrm{r}=-0.73$; regression coefficient \pm standard error: $-0.159 \pm 0.011$, $\mathrm{p}<0.001)$ : the cases $(\mathrm{r}=-0.75$, regression coefficient $\pm S E$ : $-0.143 \pm 0.013, \mathrm{p}<0.001)$, and the controls ( $\mathrm{r}=-0.68$, regression coefficient $\pm \mathrm{SE}:-0.170 \pm 0.020, \mathrm{p}<0.001)$. As also shown in Fig 1, over the whole range of apo(a) phenotypes, cases had higher levels of $\mathrm{Lp}(\mathrm{a})$ than controls.

Table 2 compares the serum levels of lipids, lipoproteins, apolipoproteins, and $\mathrm{Lp}(\mathrm{a})$ in subjects grouped according to their Lp(a) levels. Group V subjects had higher $(\mathrm{p}<0.05)$ serum levels of apo B and TC than Group I subjects, as assessed by the multiple comparison method of Dunnette. Lp(a) levels in Groups II, III, IV, and V were significantly $(\mathrm{p}<0.05)$ higher than those in Group I, as expected. The linear trends of apo B, TC, and Lp(a) levels across the quintile groups of $\mathrm{Lp}(\mathrm{a})$ were significant, as assessed by ANOVA.

Table 3 shows the clinical characteristics of patients with MI (cases) and the normal controls, and the frequency distribution of apo(a) isoform phenotypes. The cases were older and there were significantly $(\mathrm{p}<0.05)$ more male subjects (85\% vs $74 \%$ ) and smokers (61\% vs $38 \%$ ) than the controls. BMI and prevalence of HT and DM were not different between the cases and controls. The cases had relatively more subjects in Groups II, III, and V compared with the controls, as assessed by the chi-square test. Increasing $\mathrm{Lp}$ (a) levels were associated with an increased prevalence of MI, as assessed by the Mantel-Haenszel chi-squared analysis. The apo(a) phenotypes were also distributed 
Table 2 Serum Levels of Lipids, Lipoproteins, and Apolipoproteins in Patients Grouped According to Quintile Values of Serum Levels of Lipoprotein(a) [Lp(a)]

\begin{tabular}{|c|c|c|c|c|c|}
\hline & $\begin{array}{c}\text { Group I } \\
\text { (Quintile I) }\end{array}$ & $\begin{array}{c}\text { Group II } \\
\text { (Quintiles II) }\end{array}$ & $\begin{array}{c}\text { Group III } \\
\text { (Quintiles III) }\end{array}$ & $\begin{array}{c}\text { Group IV } \\
\text { (Quintiles IV) }\end{array}$ & $\begin{array}{c}\text { Group V } \\
\text { (Quintiles V) }\end{array}$ \\
\hline$H D L-C$ & $41.9 \pm 14.9$ & $39.9 \pm 12.5$ & $43.7 \pm 17.5$ & $38.3 \pm 12.3$ & $40.0 \pm 10.2$ \\
\hline$H D L_{2}-C$ & $27.1 \pm 11.0$ & $26.8 \pm 11.2$ & $28.6 \pm 14.8$ & $27.7 \pm 11.7$ & $31.7 \pm 9.0$ \\
\hline$H D L_{3}-C$ & $15.5 \pm 4.6$ & $16.2 \pm 3.5$ & $17.8 \pm 3.4$ & $15.5 \pm 3.3$ & $16.7 \pm 2.8$ \\
\hline Аро A-I & $112 \pm 28$ & $105 \pm 22$ & $113 \pm 31$ & $105 \pm 23$ & $104 \pm 21$ \\
\hline Aро A-II & $28.2 \pm 7.2$ & $27.3 \pm 5.6$ & $28.8 \pm 7.3$ & $26.5 \pm 6.4$ & $26.2 \pm 4.8$ \\
\hline Aро B & $96.0 \pm 30.8$ & $95.9 \pm 22.6$ & $108.1 \pm 24.3$ & $106.3 \pm 31.2$ & $112.5 \pm 31.0 * \dagger$ \\
\hline Apo C-II & $3.3 \pm 2.4$ & $3.5 \pm 1.5$ & $3.7 \pm 1.4$ & $3.5 \pm 1.6$ & $3.2 \pm 1.4$ \\
\hline Aро C-III & $9.9 \pm 8.8$ & $8.7 \pm 3.4$ & $9.9 \pm 3.5$ & $9.2 \pm 4.3$ & $7.8 \pm 2.1$ \\
\hline Aро $E$ & $5.3 \pm 3.4$ & $4.9 \pm 1.1$ & $5.2 \pm 1.4$ & $5.0 \pm 1.8$ & $5.0 \pm 1.7$ \\
\hline$T C$ & $182 \pm 40$ & $183 \pm 32$ & $204 \pm 34$ & $198 \pm 46$ & $211 \pm 47 * \dot{*}$ \\
\hline$T G$ & $145 \pm 162$ & $122 \pm 55$ & $124 \pm 55$ & $139 \pm 73$ & $106 \pm 44$ \\
\hline $\log _{e}[\operatorname{Lp}(a)]$ & $1.5 \pm 0.7$ & $2.7 \pm 0.2 *$ & $3.2 \pm 0.1 *$ & $3.6 \pm 0.1 *$ & $4.4 \pm 0.4^{* \dagger}$ \\
\hline
\end{tabular}

HDL-C, high density lipoprotein cholesterol; Apo, apolipoprotein; TC, total cholesterol; TG, triglyceride.

Data are presented as means \pm standard error, and the units of measurement for lipids and lipoproteins are $\mathrm{mg} / \mathrm{dl}$.

${ }^{*} p<0.05$ vs Group I, as assessed by the multiple comparison method of Dunnett; ${ }^{\dagger} p<0.05$, linear trend as assessed by an analysis of variance.

Table 3 Clinical Characteristics of Patients With Myocardial Infarction (Cases) and With Normal Coronary Arteries (Controls), and the Frequency Distribution of Serum Lipoprotein(a) [Lp(a)] Levels and the Apolipoprotein(a) [Apo(a)] Isoform Phenotype

\begin{tabular}{lcc}
\hline \hline & $\begin{array}{c}\text { Controls } \\
(n=92)\end{array}$ & $\begin{array}{c}\text { Patients with MI } \\
(n=101)\end{array}$ \\
\hline Age (years) & $58 \pm 14$ & $62 \pm 10^{*}$ \\
Gender (male/female) & $53 / 39$ & $86 / 15 *$ \\
Body mass index $\left(\mathrm{kg} / \mathrm{m}^{2}\right)$ & $23.0 \pm 3.3$ & $23.4 \pm 2.9$ \\
Hypertension $(\%)$ & 35 & 41 \\
Diabete mellitus $(\%)$ & 20 & 31 \\
Smokers $(\%)$ & 38 & $61 *$ \\
Quintiles of Lp(a) & & \\
I & $28(30.4 \%)$ & $13(12.9 \%)^{\dagger}$ \\
II & $18(19.6 \%)$ & $21(20.8 \%)^{*}$ \\
III & $16(17.4 \%)$ & $20(19.8 \%)^{*}$ \\
IV & $20(21.7 \%)$ & $17(16.8 \%)$ \\
V & $10(10.9 \%)$ & $30(29.7 \%)^{*}$ \\
Apo(a) isoform phenotype & & \\
I (A1-A4) & $21(22.8 \%)$ & $36(35.7 \%)^{\dagger}$ \\
II (A5-A9) & $22(23.9 \%)$ & $28(27.7 \%)^{*}$ \\
III (A10-A20) & $27(29.4 \%)$ & $21(20.8 \%)^{*}$ \\
IV (A21-A25) & $22(23.9 \%)$ & $16(15.8 \%)^{*}$ \\
\hline
\end{tabular}

${ }^{*} p<0.05$, by chi-squared analysis; ${ }^{\dagger} p<0.01$, linear trend as assessed by the Mantel-Haenszel chi-square.

differently $(p<0.01)$ in the cases and controls: the cases had lower percentages of larger isoforms (A5-A9, A10-A20, and $\mathrm{A} 21-\mathrm{A} 25)$ relative to small isoforms $(\mathrm{A} 1-\mathrm{A} 4)$ than the controls. A decrease in the size of apo(a) isoforms was associated with an increase in the prevalence of MI as assessed by the Mantel-Haenszel chi-square analysis.

Because the cases and controls differed with regard to age and gender, Lp(a) levels and serum levels of lipids, lipoproteins, and apolipoproteins were compared between the cases and controls after adjusting for age and gender by an analysis of covariance 30 Table 4 shows the age- and gender-adjusted least-square means of lipid variables in the cases and controls. Cases had significantly $(\mathrm{p}<0.05)$ lower levels of HDL-C and apo A-I and higher levels of apo B, apo C-II, and $\mathrm{Lp}(\mathrm{a})$ than the controls after considering for age and gender.

The significance of the associations among serum levels of $\mathrm{Lp}(\mathrm{a})$, apo(a) phenotype, MI-related lipid variables, and MI were examined by a logistic regression analysis after
Table 4 Age-and Gender-Adjusted Least-Square Means of Serum Levels of Lipids, Lipoproteins, Apolipoproteins, and Lipoprotein(a) in Patients With Myocardial Infarction (Cases) and With Normal Coronary Arteries (Controls)

\begin{tabular}{lcc}
\hline \hline & $\begin{array}{c}\text { Controls } \\
(n=92)\end{array}$ & $\begin{array}{c}\text { Patients with MI } \\
(n=101)\end{array}$ \\
\hline HDL-C & $43.2 \pm 1.4$ & $38.4 \pm 1.4^{*}$ \\
HDL 2 -C & $29.9 \pm 1.4$ & $26.9 \pm 1.4$ \\
HDL $-C$ & $16.0 \pm 0.5$ & $16.6 \pm 0.4$ \\
Apo A-I & $113 \pm 3$ & $104 \pm 3^{*}$ \\
Apo A-II & $28.0 \pm 0.7$ & $26.8 \pm 0.6$ \\
Apo B & $97.5 \pm 3.1$ & $109.0 \pm 2.9^{*}$ \\
Apo C-II & $3.1 \pm 0.2$ & $3.7 \pm 0.2^{*}$ \\
Apo C-III & $8.3 \pm 0.5$ & $9.7 \pm 0.5$ \\
Apo E & $4.9 \pm 0.2$ & $5.2 \pm 0.2$ \\
TC & $191 \pm 5$ & $199 \pm 4$ \\
TG & $115 \pm 10$ & $138 \pm 9$ \\
$\log _{e}[\operatorname{Lp}(a)]$ & $2.7 \pm 0.1$ & $3.4 \pm 0.1^{*}$ \\
\hline
\end{tabular}

HDL-C, high density lipoprotein cholesterol; Apo, apolipoprotein; TC, total cholesterol; $T G$, triglyceride.

Values are age- and gender-adjusted least-square means \pm standard error. ${ }^{*} p<0.05$ vs the controls, as assessed by an analysis of covariance.

controlling for age, gender, and confounding risk factors of MI (Table 5). Table 5 shows the results of a univariate logistic regression analysis. Serum $L p(a)$ levels and the apo(a) isoform phenotype were significantly associated with MI (positively and inversely, respectively), after controlling for age and gender (parameter estimate \pm standard error, $0.69 \pm 0.20$, WaldX ${ }^{2}=12.5, \mathrm{p}=0.0001$; and $-0.39 \pm 0.15$, Wald $\mathrm{X}^{2}=7.24, \mathrm{p}=0.007$; respectively, and additionally controlling for HT, DM, and current smoking status $(0.70 \pm 0.20$, WaldX ${ }^{2}=12.4, p=0.0004$; and $-0.43 \pm 0.15$, WaldX ${ }^{2}=8.17$, $\mathrm{p}=0.004$; respectively), suggesting that $\mathrm{Lp}(\mathrm{a})$ and the apo(a) isoform phenotype are independent indicators of MI. As also shown in Table 5, HDL-C and apo A-I levels were inversely and apo B levels were positively related to MI, independent of age and gender.

Table 5 also shows the results of a multivariate logistic regression analysis. When the apo(a) isoform phenotype was included in the model, the association between serum $\mathrm{Lp}$ (a) levels and MI remained significant after controlling for age and gender $\left(0.61 \pm 0.25\right.$, Wald $\left.\mathrm{X}^{2}=5.92, \mathrm{p}=0.015\right)$, and additionally controlling for HT, DM, and current 
Table 5 Logistic Regression Analysis of the Association of Serum Lipoprotein(a) [Lp(a)] Levels, the Apolipoprotein(a) [Apo(a)] Phenotype, and Serum Lipoprotein and Apolipoprotein Levels With Myocardial Infarction After Adjusting for Age, Gender, and Other Factors

\begin{tabular}{|c|c|c|c|c|c|c|}
\hline \multirow{3}{*}{ Independent variables } & \multicolumn{6}{|c|}{ Adjusted for effects } \\
\hline & \multicolumn{3}{|c|}{ Age and gender } & \multicolumn{3}{|c|}{$A l l^{*}$} \\
\hline & $\begin{array}{l}\text { Parameter estimates } \\
\pm \text { standard error }\end{array}$ & Wald $\mathrm{X}^{2}$ & $p$ value & $\begin{array}{l}\text { Parameter estimates } \\
\pm \text { standard error }\end{array}$ & Wald $\mathrm{X}^{2}$ & $p$ value \\
\hline \multicolumn{7}{|l|}{ Univariate model } \\
\hline \multicolumn{7}{|c|}{ [including either Lp (a) or apo(a) phenotype] } \\
\hline $\operatorname{Lp}(a)$ & $0.69 \pm 0.20$ & 12.5 & 0.0001 & $0.70 \pm 0.20$ & 12.4 & 0.0004 \\
\hline Apo(a) phenotype & $-0.39 \pm 0.15$ & 7.24 & 0.007 & $-0.43 \pm 0.15$ & 8.17 & 0.004 \\
\hline$H D L-C$ & $-0.65 \pm 0.32$ & 4.13 & 0.042 & $-0.61 \pm 0.33$ & 3.52 & 0.061 \\
\hline Apo A-I & $-0.91 \pm 0.32$ & 8.39 & 0.004 & $-0.93 \pm 0.32$ & 8.41 & 0.004 \\
\hline Apo $B$ & $0.65 \pm 0.32$ & 4.05 & 0.044 & $0.56 \pm 0.33$ & 2.81 & 0.094 \\
\hline \multicolumn{7}{|l|}{ Multivariate analysis } \\
\hline \multicolumn{7}{|c|}{ [including both Lp (a) and apo(a) phenotype] } \\
\hline$L p(a)$ & $0.61 \pm 0.25$ & 5.92 & 0.015 & $0.58 \pm 0.26$ & 5.14 & 0.023 \\
\hline Apo(a) phenotype & $-0.10 \pm 0.19$ & 0.28 & 0.60 & $-0.15 \pm 0.20$ & 0.56 & 0.46 \\
\hline
\end{tabular}

Table 6 Stepwise Logistic Regression Analysis of the Independent Association of Serum Lipoprotein(a) [Lp(a)] Levels, Apolipoprotein(a) [Apo(a)] Phenotype, and Other Factors With Myocardial Infarction

\begin{tabular}{|c|c|c|c|}
\hline \multirow{2}{*}{ Variable } & \multicolumn{3}{|c|}{ Myocardial infarction incidence } \\
\hline & Parameter estimate Standard error & Wald chi-square & $p$ value \\
\hline $\operatorname{Lp}(a)^{*}$ & $0.66 \pm 0.20$ & 10.92 & 0.001 \\
\hline Gender & $1.47 \pm 0.39$ & 14.35 & 0.000 \\
\hline Age & $0.38 \pm 0.19$ & 4.07 & 0.044 \\
\hline Aро A-I & $2.77 \pm 0.93$ & 8.91 & 0.003 \\
\hline Apo(a) phenotype $e^{\dagger}$ & $-0.42 \pm 0.16$ & 7.49 & 0.006 \\
\hline Gender & $1.52 \pm 0.39$ & 14.94 & 0.0001 \\
\hline Age & $0.47 \pm 0.19$ & 5.75 & 0.017 \\
\hline Аро A-I & $-0.98 \pm 0.33$ & 8.72 & 0.003 \\
\hline
\end{tabular}

*Model included age, gender, Lp(a), apo(a) phenotype, hypertension, diabetes, and smoking status as independent variables.

Model variables were age, gender, apo(a) phenotype, hypertension, diabetes mellitus, and smoking status.

smoking status $\left(0.58 \pm 0.26\right.$, WaldX $\left.{ }^{2}=5.14, \mathrm{p}=0.023\right)$, whereas that between the apo(a) phenotype and MI was not significant after adjusting for $\mathrm{Lp}(\mathrm{a})$ levels $(-0.10 \pm 0.19$, WaldX ${ }^{2}=0.28, \mathrm{p}=0.60$, and $-0.15 \pm 0.20$, WaldX ${ }^{2}=0.56$, $\mathrm{p}=0.46$, respectively). Because serum levels of apo $\mathrm{B}$ and TC were related to Lp(a) levels, as shown in Table 2, and serum levels of HDL-C, apo A-I, and apo C-II were related to $\mathrm{MI}$ as shown in Table 4, we added each of these variables (HDL-C, apo A-I, apo B, apo C-II, and TC) to the multivariate model, respectively, to see whether they might influence the association between $\mathrm{Lp}(\mathrm{a})$ and MI. The results were similar to those shown in the lower panel of Table 5 (data not shown). These results indicate that the association between serum $L p(a)$ levels and MI was independent of the apo(a) phenotype, but the association between the apo(a) phenotype and MI was not independent of serum $\mathrm{Lp}$ (a) levels, suggesting that the apo(a) isoform phenotype contributes to, but does not completely explain, the high Lp(a) levels in patients with MI.

A stepwise logistic regression analysis was carried out to identify significant predictive variables, with and without serum Lp(a) levels in the model (Table 6). As shown in Table 6, when age, gender, Lp(a), apo(a) phenotype, HDLC, apo A-I, apo B, apo C-II, TC, HT, DM, and current smoking status were included as independent variables, Lp(a), age, gender, and apo A-I were significant variables entered into the model, confirming the finding of the multivariate logistic regression analysis (Table 5) that $\mathrm{Lp}(\mathrm{a})$ was a significant predictor for MI, independent of the apo(a) phenotype and conventional confounding risk factors. As shown in Table 6, when Lp(a) was excluded from the model, the apo(a) phenotype, age, gender, and apo A-I entered the model as significant variables, confirming the findings of the univariate logistic regression analysis (Table 5) that the apo(a) phenotype was a significant indicator for MI, independent of conventional confounding risk factors.

\section{Discussion}

The plasma $\mathrm{Lp}(\mathrm{a})$ level is regulated by the apo(a) gene ${ }^{7}$ and has a wide range: from less than $1 \mathrm{mg} / \mathrm{dl}$ to more than $100 \mathrm{mg} / \mathrm{dl}$. In the present study, we examined the associations among serum Lp(a) level, apo(a) isoform phenotype, and MI in subjects with extremely low and high $\mathrm{Lp}(\mathrm{a})$ levels, because such subjects may provide a better understanding of the effects of the interaction of serum $L p(a)$ levels and the apo(a) phenotype on the occurrence of MI. We excluded subjects with acute $\mathrm{MI}^{23}$ and uncontrolled $\mathrm{DM}^{12}$ which are known to affect $\mathrm{Lp}(\mathrm{a})$ levels. Our findings indicate that both $\mathrm{Lp}(\mathrm{a})$ and the apo(a) isoform phenotype are significantly associated with MI, independent of confounding risk factors, and that the apo(a) phenotype 
contributes to, but does not completely explain, the increased $L p(a)$ in patients with MI. These results were not affected by serum levels of HDL-C, apo A-I, apo B, apo CII, or TC, which are related to $\mathrm{Lp}$ (a) and/or the risk of MI (Tables 2,4 ), as assessed by considering each of these variables in a multivariate logistic regression model (data not shown).

Our finding that $\mathrm{Lp}(\mathrm{a})$ is an independent predictor for MI agrees with the results of most other recent studies, ${ }^{14-17}$ except for 2 prospective studies! 18,19 Our finding that subjects with extremely high $\mathrm{Lp}$ (a) levels had small apo(a) isoforms and those with extremely low $\mathrm{Lp}(\mathrm{a})$ levels had large apo(a) isoforms confirms the findings of both our previous studies ${ }^{11,12,32}$ and other studies $8,9,33$ that an inverse relationship exists between apo(a) isoform size and plasma $\mathrm{Lp}$ (a) levels. Furthermore, this inverse relationship has been reported to be due to a difference in the rate of production, but not in the rate of catabolism, of $\mathrm{Lp}(\mathrm{a}) 3^{34}$ However, some MI patients had extremely low Lp(a) levels, and some controls had extremely high Lp(a) (Fig 1). The apo(a) that circulates in plasma is synthesized in the liver and secreted from hepatocyte where it joins LDL to form $\operatorname{Lp}(\mathrm{a})$. The fate of $\operatorname{Lp}(\mathrm{a})$ that circulates in plasma is largely unknown; therefore, an in vivo kinetic study of $\mathrm{Lp}$ (a) or apo(a) will be needed to answer these questions.

One possible mechanism for the increased serum $\operatorname{Lp}(\mathrm{a})$ levels in MI may involve its thrombogenic and fibrinolysis role. Due to its structural homology with plasminogen, 435 $\mathrm{Lp}$ (a) may compete with it for binding to endothelial and mononuclear cells as well as platelets, thereby reducing the conversion of plasminogen to plasmin and inhibiting fibrinolysis ${ }^{36-38}$ The finding that $\mathrm{Lp}(\mathrm{a})$ also binds to glycoprotein IIb further supports the important role of $\mathrm{Lp}(\mathrm{a})$ in fibrinolysis? 39 Therefore, apo(a) size polymorphism may significantly contribute to the thrombogenic potential of $\operatorname{Lp}(\mathrm{a})$. A recent study with human apo(a) transgenic mice demonstrated an in vivo effect of apo(a) on fibrinolysis and suppression of plasminogen activator-mediated thrombolysis, which may contribute to the pathology of atherosclerosis 40

Our finding that the apo(a) isoform phenotype is an independent predictor for MI confirms the results of Sandholzer et al in coronary artery disease ${ }^{33,41,42}$ However, the influence of the apo(a) isoform phenotype on the risk of MI is not independent of its effects on plasma $\mathrm{Lp}$ (a) concentrations (Tables 4, 5), as has been reported in patients with CHD ${ }^{41,42}$ It has been reported that the apo $(a)$ gene may account for more than $90 \%$ of the inter-individual difference within a pedigree ${ }^{10}$ a similar tendency to that reported by us ${ }^{12}$ However, the fact that increased $L p(a)$ levels in patients with MI can not be completely explained by differences in apo(a) isoform size suggest that other factors, such as the abnormalities of thrombosis or fibrinolysis due to increased $\mathrm{Lp}$ (a) or the vascular smooth muscle cell proliferation due to the inhibition of transforming growth factorb by $\operatorname{Lp}(a){ }^{43}$ may be involved. Because only the interaction of Lp(a), apo(a) phenotype, and history of MI were assessed in the current study, such an analysis in acute coronary syndrome, including unstable angina pectoris, should be done in a future study.

We selected angiographically defined normal subjects as controls. However, a selection bias is known to exist: angiographically defined normal subjects generally have more risk factors for coronary disease than patients with clinical symptoms but who have not been selected for angiography, because a person with both chest pain and a known risk factor, such as smoking, may be more likely to be referred for angiography than a person with just clinical symptoms. The lack of significance for the fairly substantial difference in the prevalence of DM and HT between cases and controls in the present study may be due to this bias. Thus, limitations regarding the controls may have limited the power of this study.

\section{Conclusions}

MI is associated with increased serum $L p(a)$ levels independent of the size of the circulating apo(a) isoforms.

\section{Acknowledgments}

This work was supported by grants-in-aid from the Ministry of Education, Science and Culture of Japan (Nos. 09670773, 10670221, 10670693, and 11670724), by research grants from the Ministry of Health and Welfare, and by research grants from the Fukuoka University Research Fund.

\section{References}

1. Utermann G: The mysteries of lipoprotein(a). Science 1989; 246: 904-910

2. Brunner C, Kraft HG, Utermann G, et al: Cys4057 of apolipoprotein (a) is essential for lipoprotein (a) assembly. Proc Natl Acad Sci USA 1993; 90: $11643-11647$

3. Koschinsky ML, Cote GP, Gabel B, et al: Identification of the cysteine residue in apolipoprotein (a) that mediates extracellular coupling with apolipoprotein B-100. J Biol Chem 1993; 268: 19819-19825

4. McLean JW, Tomlinson JE, Kuang WJ, et al: cDNA sequence of human apolipoprotein (a) is homologous to plasminogen. Nature 1987; 330: $132-137$

5. Mbewu AD, Durrington PN: Lipoprotein(a): structure, properties and possible involvement in thrombogenesis and atherogenesis. Atherosclerosis 1990; 85: 1-14

6. Kraft HG, Kochl S, Menzel HJ, et al: The apolipoprotein(a) gene: a transcribed hypervariable locus controlling plasma lipoprotein (a) concentration. Hum Genet 1992; 90: 220-230

7. Boerwinkle E, Leffert CC, Lin J, et al: Apolipoprotein(a) gene accounts for greater than $90 \%$ of the variation in plasma lipoprotein (a) concentrations. J Clin Invest 1992; 90: 52-60

8. Utermann G, Menzel HJ, Kraft HG, et al: Lp(a) glycoprotein phenotypes: Inheritance and relation to $\mathrm{Lp}(\mathrm{a})$-lipoprotein concentrations in plasma. J Clin Invest 1987; 80: 458-465

9. Gaubatz JW, Ghanem KI, Guevara J Jr, et al: Polymorphic forms of human apolipoprotein[a]: inheritance and relationship of their molecular weights to plasma levels of lipoprotein[a]. J Lipid Res 1990; 31: $603-613$

10. Kamboh MI, Ferrell RE, Kottke BA: Expressed hypervariable polymorphism of apolipoprotein(a). Am J Hum Genet 1991; 49: 1063-1074

11. Kikuchi S, Nakagawa A, Kobayashi K, et al: High degree of genetic polymorphism in apolipoprotein (a) associated with plasma lipoprotein (a) levels in Japanese and Chinese populations. Hum Genet 1993; 92: $537-544$

12. Hirata K, Saku K, Jimi S, et al: Serum lipoprotein(a) concentrations and apolipoprotein (a) phenotypes in the families of NIDDM patients. Diabetologia 1995; 38: $1434-1442$

13. Hirata K, Kikuchi S, Saku K, et al: Apolipoprotein(a) phenotypes and serum lipoprotein (a) levels in maintenance hemodialysis patients with/without diabetes mellitus. Kidney Int 1993; 44: 1062- 1070

14. Klausen IC, Sjol A, Hansen PS, et al: Apolipoprotein(a) isoforms and coronary heart disease in men: a nested case-control study. Atherosclerosis 1997; 132: 77-84

15. Cremer P, Nagel D, Labrot B, et al: Lipoprotein Lp(a) as predictor of myocardial infarction in comparison to fibrinogen, LDL cholesterol and other risk factors: results from the prospective Gottingen Risk Incidence and Prevalence Study (GRIPS). Eur J Clin Invest 1994; 24: $444-453$

16. Sandkamp M, Funke H, Schulte H, et al: Lipoprotein(a) is an independent risk factor for myocardial infarction at a young age. Clin Chem 1990; 36: 20-23

17. Scanu AM: Lipoprotein(a): A genetic risk factor for premature coro- 
nary heart disease. JAMA 1992; 267: 3326-3329

18. Ridker PM, Hennekens CH, Stampfer MJ: A prospective study of lipoprotein(a) and the risk of myocardial infarction. JAMA 1993; 270: $2195-2199$

19. Jauhiainen M, Koskinen P, Ehnholm C, et al: Lipoprotein(a) and coronary heart disease risk: a nested case-control study of the Helsinki Heart Study participants. Atherosclerosis 1991; 89: 59-67

20. Kronenberg F, Kathrein H, Konig P, et al: Apolipoprotein(a) phenotypes predict the risk for carotid atherosclerosis in patients with endstage renal disease. Arterioscler Thromb 1994; 14: 1405-1411

21. Gazzaruso C, Buscaglia P, Garzaniti A, et al: Association of lipoprotein (a) levels and apolipoprotein (a) phenotypes with coronary heart disease in patients with essential hypertension. J Hypertens 1997; 15: $227-235$

22. Bigot E, Robert B, Bard JM, et al: Lipoprotein(a) phenotype distribution in a population of bypass patients and its influence on lipoprotein (a) concentration. Clin Chim Acta 1997; 265: 99-111

23. Kark JD, Sandholzer C, Friedlander Y, et al: Plasma Lp(a), apolipoprotein (a) isoforms and acute myocardial infarction in men and women: a case-control study in the Jerusalem population. Atherosclerosis 1993; 98: 139-151

24. Judkins MP: A percutaneous transfemoral technique. Radiology 1967; 89: $815-821$

25. Saku K, Jimi S, Sasaki N, et al: Reduced coronary vasodilation in patients with familial hypercholesterolemia following intracoronary injection of isosorbide dinitrate. Jpn Circ J 1995; 59: 808-814

26. Takada K, Saku K, Ohta T, et al: A new case of apo A-I deficiency showing codon 8 nonsense mutation of the apo A-I gene without evidence of coronary heart disease. Arterioscler Thromb Vasc Biol 1995; 15: $1866-1874$

27. Ikeda T, Shibuya U, Sugiuchi H, et al: Automated immunoturbidimetric analysis of six plasma apolipoproteins: correlation with radioimmunodiffusion assays. J Clin Lab Anal 1991; 5: 90-95

28. Abe A, Maeda S, Makino K, et al: Enzyme-linked immunosorbent assay of lipoprotein (a) in serum and cord blood. Clin Chim Acta 1988; 177: $31-40$

29. SAS Procedures Guide, Version 6, 3rd edn. Cary, NC: SAS Institute Inc., 1990

30. SAS/STAT User's Guide, Version 6, 4th edn, Vol. 2. Cary, NC: SAS Institute Inc., 1990

31. LOGISTIC Procedure Release 607. SAS Technical Report J-119.
Cary NC: SAS Institute Inc., 1990

32. Okura Y, Saku K, Hirata K, et al: Serum lipoprotein(a) levels in maintenance hemodialysis patients. Nephron 1993; 65: 46-50

33. Sandholzer C, Hallman DM, Saha N, et al: Effects of the apolipoprotein (a) size polymorphism on the lipoprotein (a) concentration in 7 ethnic groups. Hum Genet 1991; 86: 607-614

34. Rader DJ, Cain W, Ikewaki K, et al: The inverse association of plasma lipoprotein (a) concentrations with apolipoprotein (a) isoform size is not due to differences in $\mathrm{Lp}$ (a) catabolism but to differences in production rate. J Clin Invest 1994; 93: 2758-2763

35. Eaton DL, Fless GM, Kohr WJ, et al: Partial amino acid sequence of apolipoprotein (a) shows that it is homologous to plasminogen. Proc Natl Acad Sci USA 1987; 84: 3224-3228

36. Ezratty A, Simon DI, Loscalzo J: Lipoprotein(a) binds to human platelets and attenuates plasminogen binding and activation Biochemistry 1993; 32: 4628-4633

37. Hajjar KA, Nachman RL: The role of lipoprotein (a) in atherogenesis and thrombosis. Annu Rev Med 1996; 47: 423-442

38. Miles LA, Fless GM, Levin EG, et al: A potential basis for the thrombotic risks associated with lipoprotein(a). Nature 1989; 339: $301-303$

39. Malle E, Ibovnik A, Stienmetz A, et al: Identification of glycoprotein $\mathrm{IIb}$ as the lipoprotein(a)-binding protein on platelets: Lipoprotein(a) binding is independent of an arginyl-glycyl-aspartate tripeptide located in apolipoprotein(a). Arterioscler Thromb 1994; 14: 345-352

40. Palabrica T, Liu A, Aronovitz M, et al: Antifibrinolytic activity of apolipoprotein (a) in vivo: human apolipoprotein (a) transgenic mice are resistant to tissue plasminogen activator-mediated thrombolysis. Nat Med 1995; 1: 256-259

41. Sandholzer C, Boerwinkle E, Saha N, et al: Apolipoprotein(a) phenotypes, $\mathrm{Lp}$ (a) concentration and plasma lipid levels in relation to coronary heart disease in a Chinese population: evidence for the role of the apo(a) gene in coronary heart disease. J Clin Invest 1992; 89: $1040-1046$

42. Sandholzer C, Saha N, Kark JD, et al: Apo(a) isoforms predict risk for coronary heart disease: A study in six populations. Arterioscler Thromb 1992; 12: 1214-1226

43. Harpel PC, Borth W: Identification of mechanisms that may modulate the role of lipoprotein (a) in thrombosis and atherogenesis. Ann Epidemiol 1992; 2: 413-417 